\title{
Refractory hypotension in preterm infants with adrenocortical insufficiency
}

\author{
P C Ng, C W K Lam, T F Fok, C H Lee, K C Ma, I H S Chan, E Wong
}

\begin{abstract}
Five preterm, very low birthweight infants with severe hypotension and adrenocortical insufficiency are described. The profound hypotension was resistant to volume expansion and inotrope treatment, but responded promptly to corticosteroid treatment. A human corticotrophin releasing hormone (hCRH) test performed before corticosteroid treatment showed adequate pituitary response, and the endocrine dysfunction was identified at the adrenal level. Corticosteroid treatment should be considered and could be life saving in severely hypotensive preterm infants who do not respond to conventional treatment with volume expanders and inotropes.
\end{abstract}

(Arch Dis Child Fetal Neonatal Ed 2001;84:F122-F124)

Keywords: adrenal insufficiency; corticosteroid; human corticotrophin releasing hormone (hCRH); hypotension; inotrope treatment; preterm

Adrenocortical insufficiency leading to severe systemic hypotension and circulatory collapse is considered a rare event in the newborn period. The condition has been associated with acute adrenal haemorrhage, ${ }^{1}$ generalised viral infection, ${ }^{2}$ and maternal corticosteroid usage. $^{34}$ Ill and extremely premature infants, however, form a unique group of patients because of their "immature" hypothalamicpituitary-adrenal axis which may result in decreased ability to produce stress induced release of glucocorticoids. ${ }^{5-7}$ In this report, we describe five preterm infants with persistent hypotension, which was refractory to volume expansion and inotrope treatment, but responded favourably to corticosteroid treatment.

\section{Index cases}

Table 1 summarises the clinical characteristics of the infants studied. All infants had umbilical or peripheral arterial catheters for continuous blood pressure monitoring, and were found to be hypotensive within the first 12 hours of life They received at least three doses of normal saline $(15 \mathrm{ml} / \mathrm{kg} / \mathrm{dose})$ and each infusion was given over 30 minutes. Thereafter, dopamine was started at a rate of $5-10 \mu \mathrm{g} / \mathrm{kg} / \mathrm{min}$ and the dose increased in steps of $5 \mu \mathrm{g} / \mathrm{kg} / \mathrm{min}$ every 30-60 minutes if the blood pressure remained labile. Hypotension in these infants was severe and refractory to both volume expansion and inotrope treatment. They had mottled skin with poor peripheral circulation, and arterial blood showed moderately severe metabolic acidosis ( $\mathrm{pH} 7.15-7.20$; base excess -11.8 to $-7.5 \mathrm{mmol} / \mathrm{l})$. All infants required adrenaline infusion for blood pressure support in addition to high dose dopamine and dobutamine (table 1). An intravenous dose of dexamethasone, 0.5 $\mathrm{mg} / \mathrm{kg}$ (cases 1 and 2), or a five day course of hydrocortisone, $1 \mathrm{mg} / \mathrm{kg} /$ dose, given every four hours (cases 3, 4, and 5) was introduced when both volume expanders and inotropes failed to sustain a mean arterial blood pressure above 20 $\mathrm{mm} \mathrm{Hg}$. Two of the three infants (cases 3 and 5) started on hydrocortisone remained hypotensive two hours after treatment and were subsequently given a single dose of dexamethasone. All infants responded promptly when a "sufficient" dose of corticosteroid had been administered, and the inotropes could be decreased within 50 minutes to three and a half hours. All inotropes were discontinued between 28 and 54 hours after the start of corticosteroid treatment. Figure 1 shows the blood pressure profiles of the infants before and after corticosteroid treatment. None of the infants experienced further hypotensive episodes during the following week.

As the signs and symptoms during the acute hypotensive episode closely mimicked the clinical presentation of septicaemic shock, all infants underwent sepsis screening and were started on broad spectrum antibiotics. Cultures from blood, urine, and cerebrospinal fluid were sterile. Serial C reactive protein concentrations were consistently less than $9.9 \mathrm{mg} / \mathrm{l}$ (normal $<12.0 \mathrm{mg} / \mathrm{l}$ ). ${ }^{8}$ Echocardiograms obtained in all cases showed normal cardiac anatomy with satisfactory function, and no

Accepted 6 October 2000

Table 1 Clinical characteristics of the five steroid responsive infants

\begin{tabular}{|c|c|c|c|c|c|c|c|c|c|c|c|c|}
\hline \multirow[b]{2}{*}{ Case } & \multirow[b]{2}{*}{$\begin{array}{l}\text { Gestational } \\
\text { age (weeks) }\end{array}$} & \multirow[b]{2}{*}{$\begin{array}{l}\text { Birth } \\
\text { weight (g) }\end{array}$} & \multirow[b]{2}{*}{$\begin{array}{l}\text { Sex } \\
(M / F)\end{array}$} & \multicolumn{2}{|c|}{ Apgar scores } & \multirow{2}{*}{$\begin{array}{l}\text { Antenatal } \\
\text { dexamethasone } \\
\text { treatment (doses) }\end{array}$} & \multirow{2}{*}{$\begin{array}{l}\text { Time between } \\
\text { the last dose of } \\
\text { antenatal } \\
\text { dexamethasone } \\
\text { and delivery (h) }\end{array}$} & \multirow{2}{*}{$\begin{array}{l}\text { Lowest blood } \\
\text { pressure before } \\
\text { corticosteroids } \\
\text { (systolic/diastolic } \\
\text { (mean) } \mathrm{mm} \mathrm{Hg} \text { ) }\end{array}$} & \multicolumn{3}{|c|}{$\begin{array}{l}\text { Maximum dose of inotropes before } \\
\text { corticosteroid treatment }\end{array}$} & \multirow[b]{2}{*}{ Outcomes } \\
\hline & & & & $1 \mathrm{~min}$ & $5 \mathrm{~min}$ & & & & $\begin{array}{l}\text { Dopamine } \\
(\mu \mathrm{g} / \mathrm{kg} / \mathrm{min})\end{array}$ & $\begin{array}{l}\text { Dobutamine } \\
(\mu \mathrm{g} / \mathrm{kg} / \mathrm{min})\end{array}$ & $\begin{array}{l}\text { Adrenaline } \\
(\mu \mathrm{g} / \mathrm{kg} / \mathrm{min})\end{array}$ & \\
\hline 1 & 28.6 & 985 & $\mathrm{~F}$ & 2 & 6 & 1 & 4 & $16 / 8(11)$ & 32 & 30 & 4 & CLD \\
\hline 2 & 24.7 & 660 & $\mathrm{~F}$ & 3 & 7 & 0 & - & $23 / 12(16)$ & 60 & 30 & 1.6 & CLD \\
\hline 3 & 25.0 & 670 & $\mathrm{~F}$ & 4 & 9 & 2 & 33 & $16 / 10(12)$ & 60 & 30 & 4.4 & Died, respiratory failure \\
\hline 4 & 23.9 & 770 & M & 5 & 9 & 2 & 24 & $28 / 15(20)$ & 42 & 40 & 2 & $\begin{array}{l}\text { Died, PIE, respiratory } \\
\text { failure }\end{array}$ \\
\hline 5 & 28.6 & 1055 & M & 9 & 10 & 2 & 64 & $26 / 10(15)$ & 40 & 20 & 0.5 & Alive and well \\
\hline
\end{tabular}

CLD, Chronic lung disease; PIE, pulmonary interstitial emphysema. 


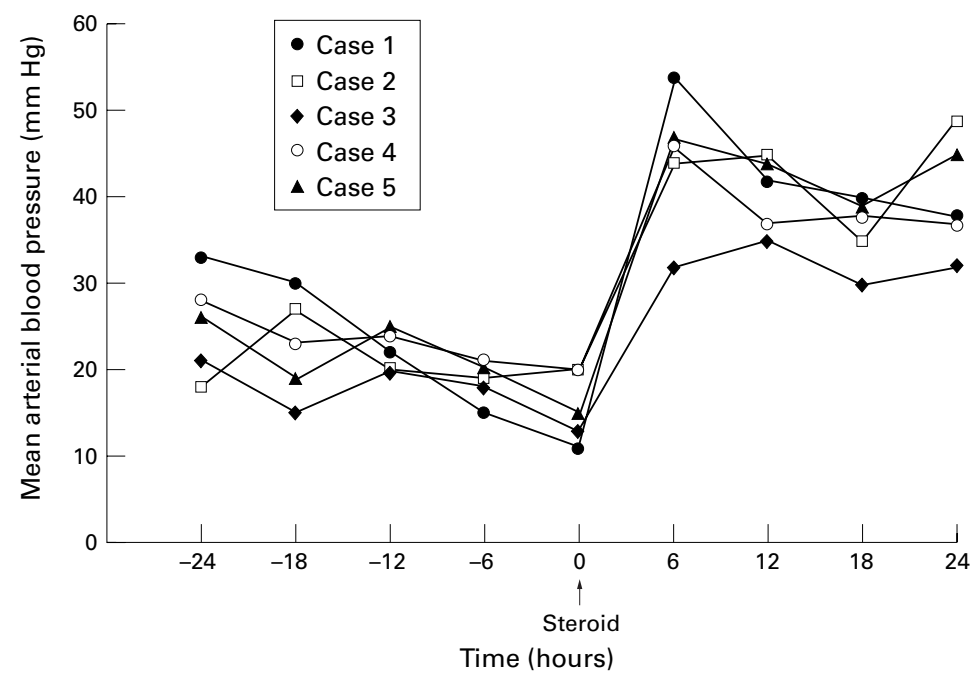

Figure 1 Mean arterial blood pressure of the index cases before ( -24 to -6 hours) and after ( +6 to +24 hours) corticosteroid treatment. The time of administration of corticosteroid (0 hours) is indicated.

significant patent ductus arteriosus was noted. Parental consent for the human corticotrophin releasing hormone (hCRH) test was obtained for each patient, and the tests were performed before administration of corticosteroid. The method of performing the hCRH test in very low birthweight (VLBW) infants has been previously described, ${ }^{9}$ and table 2 summarises their adrenocorticotrophic hormone (ACTH) and cortisol responses. The results suggest normal ACTH response, indicating that the pituitary reserve was adequate and the endocrine gland reacted normally to exogenous hCRH stimulation. In contrast, adrenal cortisol secretion was severely curtailed (table 2). One infant (case 1) had a repeated hCRH test at 5 weeks of age, and the results (the peak plasma ACTH and serum cortisol concentrations were $18.3 \mathrm{pmol} / 1$ and $632 \mathrm{nmol} / 1 \mathrm{respec}-$ tively) suggest that both pituitary and adrenal function were normal at this stage. Patients 2 and 5 suffered from severe lung disease and were started on a three week dose tapering course of dexamethasone, ${ }^{10}$ and did not receive a second test. Inotrope administration was, however, started again for patients 3 and 4 when they developed respiratory and multiorgan failure before their deaths on days 20 and 12 respectively.
There were two other VLBW infants (cases 6 and 7) within the same study period (November 98 to March 2000) who had severe hypotension requiring adrenaline treatment. Both were unresponsive to dexamethasone treatment, and the hCRH test showed normal pituitary and adrenal function (table 2). Echocardiograms of these infants showed severely impaired cardiac contractility, and the underlying cause of the hypotension was probably perinatal hypoxia or ischaemia. The pituitary and adrenal responses to hCRH (between day 5 and 7$)$ in VLBW infants $(n=38)$ who did not require adrenaline or corticosteroid for blood pressure support during the same study period - that is, infants of a concurrent studyare also summarised in table 2 for comparison. The results suggest that the basal plasma ACTH concentrations and those after stimulation were not significantly different between the steroid responsive infants and the group of VLBW infants ( $p>0.80$, analysis of variance with repeated measures), whereas both basal serum cortisol concentrations and those after stimulation were significantly lower in the steroid responsive infants $(p<0.007$, analysis of variance with repeated measures).

\section{Discussion}

Hypotension is a common occurrence in preterm VLBW infants. ${ }^{11}$ In most situations, low blood pressure is the result of hypovolaemia, haemorrhage, high mechanical ventilatory pressure, and infection. Severe hypotension secondary to adrenocortical insufficiency is rare $^{7}$ and may mimick the clinical presentation of septicaemic shock. ${ }^{12}$ This pathological process is easily overlooked ${ }^{12}$ and may be fatal if left untreated. ${ }^{13}$

All five steroid responsive infants were under severe stress at the time of the hCRH test, and serum cortisol concentrations before and after stimulation were low when compared with other VLBW infants within the same study period (table 2). Hypotension was profound and resistant to both volume expansion and inotrope treatment. There was no prompt or sustained response to the administration of adrenaline, as would be expected if this were effective treatment. In contrast, the brisk response to corticosteroid strongly suggests a diagnosis of adrenocortical insufficiency. We

Table 2 Plasma adrenocorticotrophic hormone $(A C T H)$ and serum cortisol concentrations before and after stimulation with human corticotrophin releasing hormone (hCRH)

\begin{tabular}{|c|c|c|c|c|c|c|c|c|}
\hline & \multicolumn{4}{|c|}{$A C T H(p m o l / l)$} & \multicolumn{4}{|c|}{ Cortisol (nmol/l) } \\
\hline & $0 \mathrm{~min}$ & $15 \mathrm{~min}$ & $30 \mathrm{~min}$ & $60 \mathrm{~min}$ & $0 \mathrm{~min}$ & $15 \mathrm{~min}$ & $30 \mathrm{~min}$ & $60 \mathrm{~min}$ \\
\hline \multicolumn{9}{|l|}{ Steroid responsive infants } \\
\hline Case 1 & 4.5 & 10.1 & 10.1 & 9.2 & 83 & 91 & 108 & 166 \\
\hline Case 2 & 7.2 & 16.6 & 16.2 & 15.2 & 93 & 189 & 250 & 234 \\
\hline Case 3 & 3.1 & 18.2 & 16.8 & - & 137 & 217 & 211 & - \\
\hline Case 4 & 2.9 & 10.5 & 7.3 & 6.2 & 79 & 134 & 170 & 199 \\
\hline Case 5 & 2.9 & 12.5 & 11.2 & 12.0 & 37 & 98 & 82 & 94 \\
\hline \multicolumn{9}{|l|}{ Non-responsive infants } \\
\hline Case 6 & 5.0 & 7.9 & 6.0 & 5.3 & 995 & 1031 & 1101 & 1046 \\
\hline Case 7 & 7.4 & 15.7 & 15.3 & 13.7 & 314 & 355 & 477 & 441 \\
\hline VLBW infants $(n=38)$ & $5.6(0.5)$ & $13.6(1.6)$ & $12.1(1.4)$ & $9.8(1.3)$ & $246(20)$ & $350(26)$ & $471(27)$ & $431(31)$ \\
\hline
\end{tabular}

The bottom row represents results obtained from our concurrent study in which 38 very low birthweight (VLBW) infants were subjected to the hCRH test between day 5 and 7 of life within the same study period. Values are the mean (SEM). 
were initially surprised to note that a short course of hydrocortisone or a single dose of dexamethasone could reverse the hypotensive process, but other investigators have observed similar effects with one dose of dexamethasone $^{1415}$ or physiological doses of hydrocortisone. ${ }^{7}$ We postulated that the prompt action and the prolonged effect of dexamethasone may be associated with its strong potency, long half life, and the large therapeutic dose used. Two patients (cases 3 and 5) did not initially respond to the relatively low dose course of hydrocortisone, but responded readily to a single intravenous dose of dexamethasone. Whether a pharmacological dose of corticosteroid is required to sustain the blood pressure of these highly stressed infants remains to be determined.

The absence of a cortisol surge and the normal pituitary response to exogenous hCRH in the steroid responsive cases suggest that the endocrine dysfunction is probably at the adrenal level. Although the exact pathogenesis of adrenocortical insufficiency in preterm infants has not been fully elucidated, complex changes in the hypothalamic-pituitary-adrenal axis occur soon after birth with regard to modulation of hormone secretion and corticosteroid metabolism. ${ }^{16}{ }^{17}$ Term infants adapt quickly to such postnatal changes and show a normal response to stress by the end of the first week. ${ }^{18}$ This transitional process has been postulated to be delayed, possibly because of deficiencies in intermediate enzymes, in very premature infants. ${ }^{6} 1920$ Despite recent studies using hCRH stimulation tests ${ }^{92122}$ and the synacthen test $^{11}$ suggesting that the hypothalamicpituitary-adrenal axis in VLBW infants is highly reactive and their ACTH and cortisol responses are comparable with those seen in older infants and adults, individual hormonal responses, particularly in extremely premature infants, can be highly variable. ${ }^{22}$ In addition, an inverse relation between gestational age and serum cortisol concentration has been observed. ${ }^{22}{ }^{23}$ Hence, it is likely that a proportion of extremely preterm infants have an immature hypothalamic-pituitary-adrenal axis, resulting in clinical and biochemical adrenocortical insufficiency. Our results also raise the possibility that the pituitary centre may be functionally more mature and active than the adrenals at this stage of human development.

In conclusion, we have shown that adrenocortical insufficiency in VLBW babies may closely mimick the clinical presentation of septicaemic shock and present with refractory hypotension in the first week of life. To our knowledge, this is the first report to show that the pituitary gland responds appropriately to stress, and that the endocrine dysfunction is probably at the adrenal level. In contrast with the classical Addisonian crisis, adrenocortical insufficiency in preterm infants is likely to be transient and to require only a short period of corticosteroid replacement. Corticosteroid treatment should be considered and could be life saving in severely hypotensive preterm infants who do not respond to the conventional treatments of volume expansion and inotrope therapy.

1 Klemm W, Bierich JR, Moller H, Nolte K. Acute adrenal haemorrhage in newborn infants: the importance of early diagnosis. Monatsschrift fur Kinderheikunde 1976;124:1069.

2 Bahrani M, Boxerbaum B, Gilger AP, et al. Generalized herpes simplex and hypoadrenocorticism. A case associated with adrenocortical insufficiency in a prematurely born male: clinical, virologic, ophthalmological, and metabolic male: clinical, virologic, ophthalmological, and metabolic studies. American

3 Grajwer LA, Lilien LA, Pildes RA. Neonatal subclinical adrenal insufficiency. Result of maternal steroid therapy. FAMA $1977 ; 238: 1279-80$

4 Oppenheimer EH. Lesions in the adrenals of an infant following maternal corticosteroid therapy. Fohns Hopkins Medical fournal 1964;114:146-51.

5 Watterberg KL, Scott SM. Evidence of early adrenal insufficiency in babies who develop bronchopulmonary dysplasia. Pediatrics 1995;95:120-5.

6 Thomas S, Murphy JF, Dyas J, et al. Response to ACTH in the newborn. Arch Dis Child 1986;61:57-60.

7 Helbock HJ, Insoft RM, Conte FA. Glucocorticoidresponsive hyoptension in extremely low birth weight newresponsive hyoptension in extrem
borns. Pediatrics 1993;92:715-17.

$8 \mathrm{Ng}$ PC, Cheng SH, Chui KM, et al. Diagnosis of late-onset neonatal sepsis with cytokines, adhesion molecule, and C-reactive protein in preterm very low birth weight infants. Arch Dis Child 1997;77:F221-7.

$9 \mathrm{Ng}$ PC, Wong GWK, Lam CWK, et al. The pituitaryadrenal responses to exogenous human corticotropinreleasing hormone in preterm, very low birth weight infants. F Clin Endocrinol Metab 1997;82:797-9.

$10 \mathrm{Ng}$ PC. The effectiveness and side effects of dexamethasone in preterm infants with bronchopulmonary dysplasia. Arch Dis Child 1993;68:330-6.

11 Bourchier D, Weston PJ. Randomised trial of dopamine compared with hydrocortisone for the treatment of hypotensive very low birth weight infants. Arch Dis Child 1997; 76:F174-8.

12 Hatherill M, Jones G, Lim E, et al. Procalcitonin aids diagnosis of adrenocortical failure. Lancet 1997;350:1749-50.

13 Brosnan CM, Gowing NFC. Lession of the week: Addison's disease. BMF 1996;312:1085-7.

14 Fauser A, Pohlandt F, Bartmann P, et al. Rapid increase of blood pressure in extremely low birth weight infants after a single dose of dexamethasone. Eur $\mathcal{f}$ Pediatr 1993;152:354-6.

15 Gaissmaier RE, Pohlandt F. Single dose dexamethasone treatment of hypotension in preterm infants. $\mathcal{f}$ Pediatr 1999;134:701-5.

16 Winter JSD. In: Polin RA, Fox WW, eds. Fetal and neonatal physiology. Philadelphia: WB Saunders, 1992;2:1829-41.

$17 \mathrm{Ng}$ PC. The fetal and neonatal hypothalamic-pituitaryadrenal axis. Arch Dis Child 2000;82:F250-4.

18 Sperling MA. Newborn adaptation: adrenocortical hormones and ACTH. In: Tulchinsky D, Ryan KJ, eds. Maternal-fetal endocrinology. Philadelphia: WB Saunders, 1980;389-91.

19 Hingre RV, Gross SJ, Hingre KS, et al. Adrenal steroidogenesis in very low birth weight preterm infants. $\mathcal{F}$ Clin Endocrinol Metab 1994;78:266-70.

20 Lee MM, Rajagopalan L, Berg GJ, et al. Serum adrenal steroid concentrations in preterm infants. $\mathcal{F}$ Clin Endocrinol Metab 1989;69:1133-6.

21 Hanna C, Keith L, Colasurdo MA, et al. Hypothalamic pituitary adrenal function in the extremely low birth weight infant. F Clin Endocrinol Metab 1993;76:384-7.

22 Ng PC, Wong GWK, Lam CWK, et al. Pituitary-adrenal response in preterm, very low birth weight infants after treatment with antenatal corticosteroids. 7 Clin Endocrinol Metab 1997;82:3548-52.

23 Scott SM, Watterberg KL. Effect of gestational age, postnatal age and illness on plasma cortisol concentrations in premature infants. Pediatr Res 1995;37:112-16. 